Murmúrations:

Journal of

Transfórmative

Systemic

Practice

\title{
How can we further embed systemic social work while working in this way?
}

\author{
Nana Bonsu
}

\section{Volume 3}

\section{Issue 1}

\section{Autumn 2020}

\section{Keywords:}

systemic social work, organisational response, coronavirus, Black Lives Matter, working from home, baking, pandemic

\section{Citation Link}

\section{Abstract}

This paper will explore my experiences of an organisational response to the pandemic of COVID-19, whilst simultaneously on a systemic journey to transform practice. I will use a number of systemic ideas as a means of helping me to make sense of my experiences. These ideas will draw upon the domains model (Lang et al, 1990) safe uncertainty (Mason, 2019) and social constructionism (McNamee and Gergen, 1992). I will interweave personal reflections and demonstrate a synergy between my personal and professional self.

Writing this paper has helped me to reflect on the importance of ensuring that as an organisation we pay due diligence to holding onto our systemic identity. The shifts that have occurred as a result of this pandemic and the likely consequences of austerity measures, could invite a narrowing in how we position ourselves with each other and our systemic selves. It is for these reasons that we have to hold onto expansion so we do not become reductionist, risk averse and hopeless. 


\section{Personal Context}

I work in an inner-city London local authority as a head of service for systemic and clinical practice. I am a black woman, British-Ghanaian, in my mid-forties with two sons. I am dual qualified, as a social worker, a family and systemic psychotherapist and advanced systemic supervisor. My parents were immigrants to London from Ghana, in the 1970's. I was born in Erith in Bexley and raised in south London. I have lived in London all my life. I have benefited from living in a diverse city and I enjoy what I regard the fusion of multiple cultures that have shaped and influenced my life, drawing upon a rich tapestry of difference.

Demographically the local authority I work in has the highest 0-17 population in London, and it is the $17^{\text {th }}$ most deprived local authority for children. $72 \%$ of the school population are non-white, the largest non-white group are from the African community. I have been in post for a year and this is the first time I have worked and lived in the same borough. Due to this, there has been a much closer alignment of my personal and professional self than I have experienced thus far in my career. One of the affordances has been that I can walk to work, as I have been doing currently as a result of the pandemic. Being close to my children's schools and our local amenities has enabled a better work/life balance. One of the potential challenges that concerned me when applying for the job, was whether living in the borough I work in, would result in an inappropriate diffusion between my professional and personal self. I sense what was partly informing my logic were ideas around professionalism that had somehow influenced me to believe that there had to be a clear demarcation between the two.

A shift in my beliefs came about following my attendance at a social work conference held by the local authority I was working in at the time. The keynote speaker was Gillian Ruch (2018) who writes extensively about relationship based social work practice. Gillian gave an anecdote of living and working in the same local authority. Gillian stated that this was quite the norm when she practiced as a social worker. Gillian described making curtains for a family she was working with. She saw children she worked with walking to school in the morning and she would have impromptu chats with them. I remember at the time marvelling at what sounded like a professional identity that was more fluid with her personal self, not restricted in the way I seemed to be at that time. Hearing Gillian speak in this way shifted my frame of what was possible with regards to how relationships with families could be constructed. I believe when we work in contexts in which risks are prevalent, there is a danger that trust is very hard to come by for both professional and family. As a result, ideas about boundaries, professionalism and othering (Nielsen, 2002) become more pronounced. The acts and functions that occur within statutory children's social work are littered with binary positions that I believe we embody, shaping our logic about what is and is not permissible. Our thinking becomes narrowed and expansion becomes harder. I believe this context can erode the potential for relationships to be more collaborative. Generally engagement is one in which the professional is tasked with the responsibility of reducing/minimising the risk, not those we work with. The challenge in changing an organisational culture to one that is more relational and systemic in approach, is the shifting of power. A move from a first order, expert position to one that is collaborative, strengths based and self-reflexive; a second order positioning. 


\section{Personal and Professional}

So these ideas about this demarcation have shifted now, as a result of the current COVID-19 pandemic. The interface of my professional and personal self has become much greater than ever before. I am primarily working at home, my sons are learning from home, not having attended school since the lockdown began. On one level we are all together but the capacity to be 'present' when we are all engaged on a device can mean that we are inhabiting other worlds simultaneously, weaving in and out of the worlds we inhabit at different times during the day. At moments, I will be curious about what they are doing and likewise they will ask questions about what I am doing. As a result of technology, meetings and contact has continued virtually. Colleagues have been in my bedroom, kitchen, conservatory and garden. This goes against the usual conventions one would follow with regards to inviting people to your home, for a particular function/event. Colleagues have seen my sons and my cat Oscar. On one occasion in a meeting, my colleagues observed me through a muted microphone tell my eldest son to put his laptop down (this was during a small argument with his younger brother) and he walked off with the laptop. Humorously my director remarked that I might need to enrol onto a teen parenting course. This helped diffuse the moment for me, my parenting act, which my colleagues would not see ordinarily, was caught on camera in such a public way. The humour from my director helped me not to be overly conscious of the moment. A family have watched me cook hamburgers during a session, as I needed to start dinner. Normally due to their commitments, our sessions are usually late on a Friday and I would be in their home. The foster carer remarked that it was good to see me in parent mode. These moments of privacy have become open to others in a manner that I would have considered unprofessional, prior to the pandemic. Not only can they see me, I can see myself, feeling at times that I am in constant surveillance. It makes me think of Foucault and his ideas around 'normalising truths' that we can inhabit (White and Epston, 1990), where we can auto-correct our behaviours based on our conditioning of social norms. I know I have the power to turn my camera off and I have done so in moments. On the whole though, I like to keep my camera on. I have adjusted to this way of working, but miss physical contact and the nuances of dialogue that come with it. I cannot pick up the non-verbal cues or I can misconstrue meaning. The turn taking of conversations can be difficult when there is a lag and the space is filled by many voices all at the same time. The ability to ponder and reflect does not quite land in the same way in front of the 'normalising gaze' of the camera lens, I somehow feel propelled to contribute. I miss the spontaneous conversations with colleagues, those quick "have you got a minute" conversations, which peppered my day and enabled movement when I felt stuck, frustrated or unsure. Now I have no idea what my colleagues are doing in their own worlds and I become organised by the politeness of not wanting to unnecessarily interrupt. So ironically, although for some of us connectivity is possible, a sense of isolation can prevail. There are individuals who have not been part of this digital world, through poverty, lack of education and ability. I am also aware of the impact child caring responsibilities have had on the ability to be "present". There can be a false illusion that as we all have a laptop, there is an equitable opportunity to still be able to perform one's roles, and this is not the case. Much like COVID19 was not an equitable disease.

My whole career I have been privileged to enter the homes of families. Home based treatment has enabled me to understand the contexts more keenly for the families I work with. Observing interactions in the moment in families' environments has helped with my formulations and interventions. I am acutely aware of my privileges in comparison to those I work with, with regards 
to ability, education and class (Burnham, 2011). This has galvanised me to create clinical services that are accessible, responsive and bespoke for those marginalised in our community. I recognise that there are children who are not able to routinely access services in the manner that they are shaped, attending the spaces that professionals inhabit. Likewise these children and young people do not always meet the criteria of thresholds, which can mean their symptomology becomes more entrenched, resulting in breakdowns in their family or placements when in care. The costs of these placements to the local authority are extremely high. The "solution" of placing the children/young person elsewhere can be very pathologising; whilst not attending to the family and wider contextual factors. We know that systemic psychotherapy helps us to understand that problems are between us and not inherent in us.

I have noted that during the early stages of the pandemic, my critical inner voice (my trusted companion), spoke quite a bit. My inner voice drew on the many aspect of my multiple selves; mother, daughter, sister, aunt, friend and colleague. My inner voice wanted to know why I was not doing more for my parents. Should I be shopping and leaving it on their doorstep? How much school work in a day is enough? Why do I not know more about how to use Google documents and any other software the school have sent? Why do I not know what the parents are talking about in the WhatsApp groups I am in? What have I missed in the school newsletters (which I never read anyway, but suddenly now they were of the upmost importance)? Should I instigate a virtual meet with friends or should I wait for them to instigate? My windows need cleaning (this is a result of being home for far too long). Why do I not know how to make bread, everyone seems to be making bread? Am I performing at work as I should because I feel tired easily and I do not want to be in another team meeting? Should I be making flapjacks in the day with my ten year old son, while working? On and on it went, this inner surveillance. I know I am not alone. I have meetings with colleagues who are attending to their children and working at the same time. A lovely experience I recall was speaking with a colleague, a male social worker whose son a toddler was in his arms and he fell asleep while we were talking. His snores were a quiet backdrop that accompanied our meeting. Another colleague, a clinical therapist her daughter is often in our team meetings. Her mother wears headphones, there's the critical voice again, and someone may read this and become concerned. I have noted how permissible this all seems now and why not? For me in the early stages of this pandemic all of these matters were challenging for me to navigate practically and morally, with time however I have settled more into the experience and the internal voice is now not so critical or loud.

I would like now to focus somewhat more on my professional context. The title for my paper came from a question posed by my director who wanted me to lead a session with my senior colleagues, using this question to frame the session. To understand his intentions, I need to give you some context. My director is male, British-Indian, a social worker, family and systemic psychotherapist, advanced systemic supervisor and has written a number of papers. He has had a track record of introducing systemic practice within a social care context: working within the "Reclaiming Social Work" model pioneered in Hackney (Goodman and Trowler, 2012). In my career I have had similar experiences of working within children's services while implementing systemic practice.

A key experience within my organisation has been my creation and implementation of our practice framework, which has family and systemic psychotherapy at its heart. The manner in which this has 
been done is multifaceted; employing clinical therapists to be co-located in the service, procuring systemic training at both practitioner and managerial levels and developing the infrastructures to enable systemic practice to land. Research regarding the positive impact of systemic psychotherapy within statutory social care, has proved to be effective (Sebba et al, 2017). I hope to see that practice privileges the importance of engendering relationships as a key determinant to change. My hope in creating the practice framework has been practitioners learning and implementing therapeutic skills to assist in managing the complexities and emotional demands of practice. The practice framework is theoretically rooted within a social constructionist epistemology, we have the ability to create the "social worlds" we wish to inhabit (Pearce, 2007). This is particularly resonant for me, having been raised in a working class neighbourhood in South London, where my social world was like an "invisible fence" (Hardy, 2008) with physical and "possibility" fences. When I say possibility fences, I am referring to what my mind could conjure up about what possibilities there were for me with regards to my education and career. I recall a childhood friend securing a place at University, she was the only person I knew in my childhood who had been offered a place and was going to University. Until she went, this had not been a possibility in my mind that I would/could do the same, as no-one I knew had done so. When it was time for me to undertake my " $A$ " levels, I deliberately chose a $6^{\text {th }}$ form college that was not in the area I lived as I wanted to experience something different. I remember being struck at how easily my white peers knew they were going to University, their parents had, older siblings had and extended family members. I would recall anxiety, hoping that I would get the required grades to get in.

My key childhood physical fences pertained to my family home, my childminder's home and my school. Within each of these worlds were rules, rituals and cultures that governed what was and was not permissible/possible. Sometimes they were in sync with each other, other times they were in opposition. I recalled when Stephen Lawrence was murdered in Eltham, my peers and I were not surprised. At that time there was an unsaid for us that you did not go beyond the physical fence of Lewisham to Eltham or Bexley, because we were black. Reflecting now I imagine it was based in all likelihood on stories of racism. These stories as a black child we paid close attention to.

These memories have come flooding back as a result of me writing this paper, which has been illuminating for me to recall. Whilst writing this paper George Floyd has been murdered in America and I sense that my recollections have been triggered by the events that have unfolded as a consequence of his death. Some difficult memories of being racially abused as a child have resurfaced for me. I know that as a result of my experiences I am keen to ensure that the vision we have in my local authority is ensuring that no matter where you are from, services must meet needs. It is interesting that the COVID-19 pandemic has resulted in the professional spaces not being utilised in the manner they were previously. The guidance requiring staff to work from home has meant that our office space is largely uninhabited. Colleagues are undertaking visits in the community. As such my intentionality of enabling therapeutic encounters to take place in spaces that are not necessarily regarded as "professional", has become even more pertinent. In my experiences of providing therapy to families in their contexts, it really helped my understanding of their contexts in a manner I would not have been able to if they just came to the clinic. One poignant memory that sticks with me was when I asked a family I was working with if I could use their toilet. The toilet door had completely come off the hinges and the toilet was located in the main corridor. I remember initially being struck by my vulnerability in using the toilet in this way. I then began to reflect on the many challenges the 
family I was working with, had to contend with. A single black mother, with two children (adolescents) who were of different sex had to share a room and they did not have a door on their toilet. The unsaid narratives that had been informed about this mother not being available when professionals contacted her, where wholly lacking in understanding of her need to work. There was a sense that her unavailability was synonymous with not wanting to work with professionals. What was missing was an understanding of the intersectionality of the social GRACES and how this informed the logic of the actions taken by this mother. This memory among many shapes my motivation for where therapeutic encounters can take place.

In practicing within a systemic social work frame, our capacity to hold in mind wider contextual matters and our attention to our power is vital. Having a vision however is not enough, we have to embody through our actions and behaviours the vision we wish to see. We have to strive to work hard to "concretise" what we believe in and support each other in doing so. So the practice framework I consider the articulation of the vision, the systemic practice is the "work" putting the vision into action.

My highest context has always been the safety of children and young people, but the manner in which we do this is so important. Remaining curious, self-reflexive and attending to issues of power are vital to ensure we do the least harm possible. I am very conscious of the "single story" (Chiamanda Ngosi Adichie, TED talk) that I experienced growing up as a result of my race, gender and class and these would be the GRACES that grab me because of my lived experiences (Totsuka, 2014). I am keen for our practice/interventions not to result in families being cut off from their inherent resources (Nielsen, 2002).

As a result of this pandemic like many other local authorities, we chose to categorise families according to an assessment of risk, as means of making decisions about the level and type of contact that would be required. We chose a RAG rating system (red, amber and green traffic lights) to help us to decide which families were most at risk. This system enabled us to determine which families required a face-to-face visit and those where a virtual visit could suffice. I believe that this process provided an element of containment in the face of such uncertainty. An interesting outcome in undertaking the process was a realisation that some families did not need to be open to our department. There have also been instances of families who were considered red, being recategorised, so the risk assessment became quite fluid, as it should. One of the challenges of this process was the potential illusion of certainty. We were predicting/assessing where harm was likely to transpire and for whom. One could say that this is the antithesis of a practice system developing systemic practice as part of our transformation journey. Early on in my systemic career I would have felt quite uncomfortable with these practices, which I would have positioned as being "unsystemic". I remember passionately learning ideas from social constructionism that for me lent themselves to a more freeing way of seeing the world. Moving away from my lived experiences as a statutory social worker within a child protection context which sought safe certainty (Mason, 2019) and privileged the domain of production (Lang et al, 1990). I do not feel that way now. Instead I welcome ideas based on fit, attending to feedback and holding the safety of children and young people as my highest context. This malleability in my beliefs and practice, has helped me to feel comfortable knowing that there are absolutely appropriate moments when we have to be in the domain of production and safe certainty. 
What I feel now is of paramount importance is one's self-reflexivity, to know where I am and what the affordances and constraints are of my positioning. What I believe my director noted when he posed the question to me, was the worry that this self-reflexivity was not meta within the organisation. Our performance team helped us track our visits and this information was shared daily. The volume of data, and the daily reminder of percentages, meant that organisationally we had only privileged that domain of production, we were in a strange loop (Pearce 2007). I believe the more we saw, the more we slavishly attended to this area of our practice. We did not inhabit other areas of the domains, explanation or aesthetics, nor did we inhabit other aspects of Mason's quadrant.

So my director's intervention was a punctuation point, that helped us firstly as a senior leadership team through my presentation to pause, take a meta position and reignite the other aspects of our systemic selves. His request also positioned me to reflect on who I am within the organisation. I say this as my role is very different to that of my colleagues in that, I create clinical services for the whole department. I provide clinical consultations for staff and partnership agencies, I work directly with children, young people, families, carers and partnership agencies. I teach and procure training, in keeping with the practice framework I created. I make strategic decisions alongside my colleagues. It is a very exciting position to be in but also because it is so different, I can at times feel that I do not quite fit in. This can then impact on my confidence, which people would not know. My director knows this about me, as we talk about it. He supports me to take risks and challenge myself, which propels me to go beyond my "possibility" fences.

In a short space of time a great deal of work had begun to bear fruit. A monitoring visit by Ofsted (October 2019) and a full Ofsted inspection (March 2020) noted very clearly the positive impact of creating a systemic framework within our department. This is extremely positive but does not go far enough to promote behavioural change. One of the most significant systemic principles that I like to discuss when teaching, undertaking consultations or direct work, is second order change. For me this is where I need to see change being sustained and embedded. The embedding of systemic ideas so that they are inherent in our logic and actions, will mean that we can actively create the culture that we all wish to see for ourselves and those we work with. Interestingly to hold onto our systemic selves in such a time as this, demonstrates for me a huge amount of hope for what can be possible regardless of the circumstances. This is not an easy journey currently. After our good Ofsted rating, COVID-19 happened. It feels unfair somehow that we have not had an opportunity to have a moment to pause and reflect about this positive outcome. Yet, we did get that outcome and I cannot let that be a subjugated story, lost in the waves of uncertainty. We would do ourselves a disservice if we privileged one discourse and did not attend to others. Resilience and hope is what we wish for those we work with, we must also give that to ourselves and each other.

One of the challenges of creating cultural change is the oscillation of power, with regards to where the change process lies and who is responsible. I say this, as I often get feedback from social workers and practitioners that appears to indicate that change can only occur with those they regard as having power, senior managers etc. It is almost as if, power is not inherent within but instead an external force that needs permission to be taken. Now, I cannot ignore contextually what may imbue this sense of powerlessness. Statutory children's services is heavily scrutinised and regulated, with significance placed upon "expertise". What I have seen over my eighteen years of practice in this sector is an erosion of social workers having "voice entitlement" (Boyd, 2018) with regards to their assessments, 
interventions and formulations; particularly within the court arena. An overreliance in my view, upon expert assessments (which certainly have a place) can lead to a sense of powerlessness and a lack of confidence in the social worker. I know when I trained as a social worker, I wanted to work with people and not spend time in an office. The bureaucracy of the social work profession and the impact on professional judgement has been well noted in literature. Munro's (2011) seminal review was seen as a significant moment in my career, as a means of illuminating this issue and espousing a need to redress the balance. Where else potentially does this sense of powerlessness happen? In our practice with those we work with. The reliance on the professional to enable and take responsibility for change, can result in those we work with not feeling confident in their own decision making and abilities. I do not believe these are wilful positions or deliberate acts, on the part of professionals; instead, systems replicate and can continue patterns without self-reflexivity.

Here is a typical example of a clinical consultation with a social work team, who were seeking support with a parenting assessment (all details have been anonymised). They are working with a mother who is addicted to substances, she has two daughters eight and five, now in foster care due to neglect. Mother's substance misuse has meant that she put her daughters at risk on a number of occasions, leaving them unsupervised or in the care of male strangers. The children's father has put himself forward as a carer. One of the worries of the team, was father's capacity to reconcile that his expartner has a substance misuse problem and therefore remains a risk to the children. Conversely in the consultation, I noted that the social work team also had hope that the mother could look after the children. This was despite significant evidence to the contrary. It was as a result of the consultation that we were able to see this similarity in positioning between the father and the social work team, isomorphism. Initially the responsibility for not attending to risk lay with the father and not "us" as professionals. The clinical consultation enabled the ability to see this pattern and shift the meaning to the social work team of the father's positioning.

In creating the clinical service, I held in mind these notions of expertise and power. I deliberately ensured that a clinical consultation would not mean a clinical therapist would immediately start direct work. Instead, the clinical consultation is an opportunity to come alongside our colleagues, pause, reflect, note patterns and support them where appropriate to undertake the interventions. We undertake clinical work when we are clear that it requires a clinical intervention that the social worker or practitioner is not able to do. The reason for this is two-fold. Firstly my belief is that for second order change to take place, power must be seen within. If change only comes about as a result of external factors, it cannot be sustained. This is also true for those who come to seek our help. I often support practitioners to begin to have what I term second order conversations with those they work with, as a means of embedment. Secondly, I have a small resource and it is inconceivable that the clinical service would be in a position to work with everyone who was referred to the service. Instead I pool resources and create bespoke training offers for the specific needs of services, as a means of holding in mind that there is more merit in a collective resource than a small one.

In returning to the question of my paper, as the head of service I have been mindful about embedment from the outset of my appointment. So interestingly the pandemic has brought this matter into sharper focus as the uncertainty could result in levels of anxiety resulting in practices that feel more knowing and comfortable. This paper has made me consider the various vantage points in an organisation and where responsibility for embedment lies. At the beginning of my appointment, I 
tended to position myself as being solely responsible for the success of systemic practice within the organisation. Reflecting on this, I realise starting a job of this magnitude, I was keen to demonstrate the value of systemic ideas within a statutory context. This was particularly so, as appointing clinical therapists took a great deal of time. Uncertainty became a constant companion and I learnt a great deal about myself during eight months of creating and operationally managing the service. What has been very endearing for me during this time has been the support from my senior colleagues who have demonstrated their commitment and support to the practice framework. The clinical service is non-statutory but is at the heart of the practice model. This can at times create a strange positioning on a continuum of being central and peripheral. The blending of systemic practice within a statutory child context has become utilised in local authorities and I am sure will continue. What is interesting for me is to begin to consider how this amalgamation will inform social work practice in the future. The intermingling of the two professions, will create systemic social workers and not a sense of "otherness" which is different or unique. This fusion will be how social work practice could be. I enjoy the affordances my dual qualification affords me and do not feel positioned to use one qualification at the behest of the other. I feel that the responsibility for developing a culture of systemic social work practice, belongs to all of us, regardless of our vantage point in the organisation.

There is an interesting juxtaposition to note that the training in systemic psychotherapy is mandatory, a first order position. It is interesting as it seemingly goes against the very values of systemic practice, or does it? I believe I can be guilty at times, if I am not reflexive, of positioning systemic psychotherapy in the binary frame, I alluded to earlier that can occur within statutory children's practice. These binaries for me can position first order as bad and second order as good, expertise as bad and collaboration as good and so on. Being clear about a vision for practice and putting together the necessary steps for that vision to flourish is not bad/wrong. I believe it is the journey in getting staff to join with this vision, where a second order position is most fitting, the domain of aesthetics (Lang et al, 1990). The practice framework inhabits the "why" aspect of the domain of aesthetics, legitimising the justification for the first order position of the training being mandatory in order for the practice framework to come into being. So these positions are symbiotic of each other, recursively intertwining to create a preferred reality for practice.

In my eighteen years' experience of practice, I have noted a tendency for local authorities to invest in practice models, but not always hold a meta position i.e. thinking about the grandiosity required for success; or change a practice model after a great deal of investment and change. In my experiences these changes have occurred when there is a change in personnel at director level or above. What this does for practitioners I believe is create a sense of anxiety/apathy about "buying into" the next practice vision. This is a really important issue for senior leaders to hold in mind, when joining organisations. It is really important to honour what went before in the creation of what needs to happen next. The local authority I am in now had a previous encounter with systemic practice. Unfortunately, it did not become embedded as it appeared there was not sufficient strategic oversight. Returning to it but this time using a "whole system" implementation, honours what went before, so it fits. I believe this enables momentum, embedment and refinement to have a greater likelihood of success. It is very brave for an organisation to declare an intent with regards to practice epistemology and remain steadfast regardless of the changes in contextual factors that will naturally occur. So below are my key ingredients for systemic embedment success currently useful for me to hold in mind in my practice. 
My recipe for organisational embedment success:

1. As a senior leadership team have a clear vision for what you want your organisation to stand for with regards to practice.

2. Be brave and commit to being vulnerable. Risks must incorporate vulnerability.

3. Invest money in your vision to come to fruition.

4. Identify where influences lie in the system and ensure those identified are clear about the expectations going forward.

5. Your vision must be articulated to all staff and those you provide services for in various ways.

6. Not everyone will come on the journey with you; that is ok, keep going.

7. Ensure there are systemic infrastructures in place that are varied in nature, to enable as many opportunities as possible for systemic ideas to be malleable.

8. Recruit systemic psychotherapists into your organisation who will help support the workforce with exposure, experimentation, teaching and embedment.

9. Ensure recording systems are reflective of your systemic vision, so that there is a synergy with all forms of practice interfaces.

10. Have a whole system approach to systemic practice, and incorporate the community, both statutory and non-statutory.

11. Use multi-varied feedback processes as a means of enabling refinement, including feedback from those you serve.

Finally let's now turn to the flapjacks that I made with my younger son, during the day. Here's a picture of our flapjacks and this is the recipe.

\section{Ingredients}

Serves 10 (allegedly)

- $125 \mathrm{~g}$ butter/margarine

- $100 \mathrm{~g}$ dark brown soft sugar

- 4 tablespoons of golden syrup

- $250 \mathrm{~g}$ of rolled oats (I used jumbo size oats)

- $40 \mathrm{~g}$ of blueberries (or whatever fruit you like)

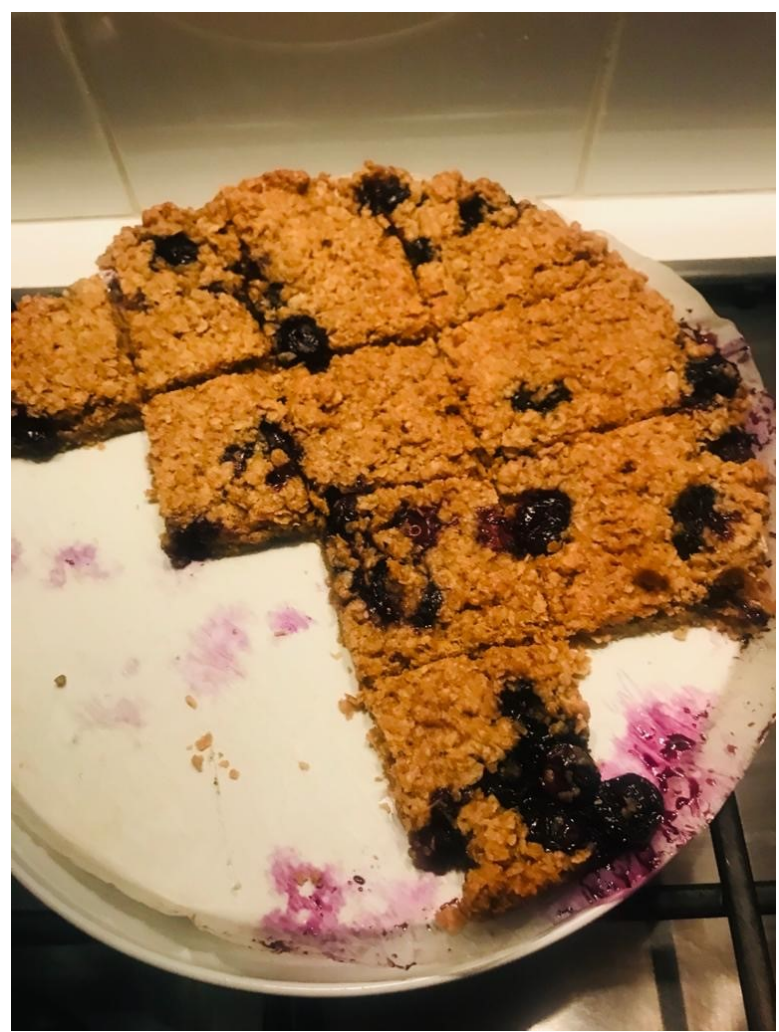




\section{Method}

- Pre-heat oven to $180 \mathrm{c} /$ Gas mark 4

- In a saucepan over low heat, combine butter, sugar and golden syrup. Be patient, don't have the heat too high and stir every so often until the sugar and butter have melted

- Stir in the oats and blueberries until they are coated in the mixture

- Put in a $20 \mathrm{~cm}$ baking tray, square or round

- Depending on how you like the texture I would bake for between 20-30mins

- I did 25 mins as I like the texture a bit gooey

- Eat and make more

\section{References}

Adichie, Chimamanda Ngozi (2009). Danger of a Single Story. https://youtu.be/D9Ihs241zeg

Boyd, Elizabeth (2018). 'Voice entitlement' narratives in supervision. Cultural and gendered influences on speaking and dilemmas in practice. In Burck, Charlotte and Daniel, Gwyn (Eds.), Mirrors and Reflections: Processes of Systemic Supervision. Routledge

Burnham, John (2011). Developments in Social GRRAACCEESS: visible-invisible and voiced-unvoiced. In Krause, Britt-Inga (Ed.), Culture and Reflexivity in Systemic Psychotherapy: Mutual Perspectives. London: Karnac.

Goodman, Steve and Trowler, Isabelle (Eds.) (2012). Social Work Reclaimed: Innovative Frameworks for Child and Family Social Work Practice. Oxford: Jessica Kingsley Publishers.

Hardy, Kenneth (2008). Race, Reality, and Relationships: Implications for the Re-Visioning of Family Therapy. In McGoldrick, Monica and Hardy, Kenneth (Eds.), Re-Visioning Family Therapy: Race, Culture and Gender in Clinical Practice. New York: Guildford Press.

Lang, Peter; Little, Martin and Cronen, Vernon (1990). The systemic professional: domains of action and the question of neutrality. Human Systems. Journal of Consultation and Management, 1, 39-56.

Mason, Barry (2019). Re-visiting safe uncertainty: six perspectives for clinical practice and the assessment of risk. Journal of Family Therapy, 41, 3, 343-356. https://doi.org/10.1111/1467-6427.12258

McNamee, Sheila and Gergen, Kenneth (Eds.) (1992). Therapy as Social Construction. London: Sage.

Munro, Eileen (2011). The Munro Review of Child Protection: Final Report A Child Centred System. Department for Education.

Nielsen, Jorn (2002). Working in the Grey Zone: the challenge for supervision in the area between therapy and social control. In Campbell, David and Mason, Barry (Eds.) Perspectives on Supervision. London: Karnac.

Pearce, W. Barnett (2007). Making Social Worlds: A Communication Perspective. London: Blackwell Publishing. Ruch, Gillian; Turney, Danielle and Ward, Adrian (Eds.) (2018). Relationship Based Social Work: Getting to the Heart of Practice. Oxford: Jessica Kingsley Publishers. 
Sebba, Judy; Luke, Nikki; McNeish, Di and Rees, Alun (2017). Children's Social Innovation Programme: final evaluation report. Department for Education.

White, Michael and Epston, David (1990). Narrative Means to Therapeutic Ends. London: W.W. Norton and Company.

Totsuka, Yoko (2014). 'Which aspects of the social GGRRAAACCEEESSS grab you most?' The social GGRRAAACCEEESSS exercise for a supervision group to promote therapists' self-reflexivity. Journal of Family Therapy, 36, 1, 86-106. https://doi.org/10.1111/1467-6427.12026

\section{Author}

Nana Bonsu, is a dual qualified social worker and family and systemic psychotherapist. Nana is Head of Service for Systemic, Clinical Practice and Adolescent Services in Croydon. Since her appointment in June 2019, Nana has developed the Croydon practice model and the creation of an in-house clinical service. She has been practising for 18 years, working with families in statutory children's services and child and adolescent mental health services. Nana has developed clinical services within a statutory setting in the last three local authorities she has worked in. She is passionate about teaching and has been a teaching consultant for Goldsmiths College, London University on their BA and MSc social work programmes. Nana has also taught at the Institute of Family Therapy and teaches staff in Croydon via the Croydon Family Therapy Academy.

E-mail: nana.bonsu@croydon.gov.uk

\section{Citation}

Bonsu, Nana (2020). How can we further embed systemic social work while working in this way?

Murmurations: Journal of Transformative Systemic Practice, 3, 1, 68-79. https://doi.org/10.28963/3.1.14 